Supplement of

\title{
Measurement report: Spatial variations in ionic chemistry and water-stable isotopes in the snowpack on glaciers across Svalbard during the 2015-2016 snow accumulation season
}

Elena Barbaro et al.

Correspondence to: Andrea Spolaor (andrea.spolaor@cnr.it)

The copyright of individual parts of the supplement might differ from the CC BY 4.0 License. 
Table S1. Performance of analytical methods applied at Hornsund, Venice, and Uppsala laboratories. Method detection limit (MDL) was calculated as three times the standard deviation of the procedural blank (ultrapure water). Error (\%) and relative standard deviation (RSD\%) were determined to evaluate the trueness and precision of each method, respectively.

\begin{tabular}{|c|c|c|c|c|c|c|c|c|c|c|c|c|}
\hline & \multicolumn{4}{|c|}{ Hornsund method } & \multicolumn{4}{|c|}{ Venice method } & \multicolumn{4}{|c|}{ Uppsala method } \\
\hline & $\begin{array}{l}\text { Linear } \\
\text { range } \\
\mathrm{mg} / \mathrm{L}\end{array}$ & $\begin{array}{c}\mathrm{MDL} \\
(\mathrm{mg} / \mathrm{L})\end{array}$ & $\begin{array}{c}\text { Error } \\
\%\end{array}$ & $\begin{array}{c}\text { RSD } \\
\%\end{array}$ & $\begin{array}{l}\text { Linear } \\
\text { range } \\
\mathrm{mg} / \mathrm{L}\end{array}$ & $\begin{array}{c}\text { MDL } \\
(\mathrm{mg} / \mathrm{L})\end{array}$ & $\begin{array}{c}\text { Error } \\
\%\end{array}$ & $\begin{array}{c}\text { RSD } \\
\%\end{array}$ & $\begin{array}{l}\text { Linear } \\
\text { range } \\
\mathrm{mg} / \mathrm{L}\end{array}$ & $\begin{array}{c}\text { MDL } \\
(\mathrm{mg} / \mathrm{L})\end{array}$ & Error $\%$ & RSD \% \\
\hline $\mathrm{Cl}^{-}$ & $0.003-20$ & 0.003 & -3 & 5 & $0.001-4$ & 0.2 & -9 & 7 & & & & \\
\hline $\mathrm{Br}^{-}$ & $0.004-1$ & 0.004 & 0 & 1 & $0.002-0.2$ & 0.002 & -5 & 6 & & & & \\
\hline $\mathrm{SO}_{4}{ }^{2-}$ & $0.003-20$ & 0.003 & -3 & 2 & $0.002-8$ & 0.07 & 4 & 3 & & & & \\
\hline $\mathrm{NO}_{3}^{-}$ & $0.006-10$ & 0.006 & -2 & 1 & $0.002-2$ & 0.04 & -8 & 4 & & & & \\
\hline $\mathbf{N a}^{+}$ & $0.03-15$ & 0.03 & 0 & 2 & $0.1-10$ & 0.05 & 4 & 4 & $0.001-1$ & 0.004 & $< \pm 5 \%$ & 1 \\
\hline $\mathbf{N H}_{4}^{+}$ & $0.02-2$ & 0.02 & n.d. & n.d. & $0.1-10$ & 0.005 & n.d. & n.d. & $0.001-1$ & 0.001 & n.d. & 0.5 \\
\hline $\mathbf{K}^{+}$ & $0.05-5$ & 0.05 & -1 & 2 & $0.1-10$ & 0.02 & -8 & 1 & $0.001-1$ & 0.002 & $< \pm 5 \%$ & 2.0 \\
\hline $\mathrm{Mg}^{2+}$ & $0.05-5$ & 0.05 & -20 & 3 & $0.1-10$ & 0.007 & -9 & 1 & $0.001-1$ & 0.001 & $< \pm 5 \%$ & 0.4 \\
\hline $\mathrm{Ca}^{2+}$ & $0.08-25$ & 0.08 & -2 & 2 & $0.1-10$ & 0.04 & -1 & 1 & $0.001-1$ & 0.006 & $< \pm 5 \%$ & 5 \\
\hline
\end{tabular}

Figure S1. Ion balance of the total load for each glacier sampled during the C2S3 project. $\mathrm{X}^{-}$ denotes missing anions in the balance. Frequently in natural waters $\mathrm{X}^{-}$is found to be composed mostly of $\mathrm{HCO}_{3}{ }^{-}$, which cannot be determined with ion chromatography. 


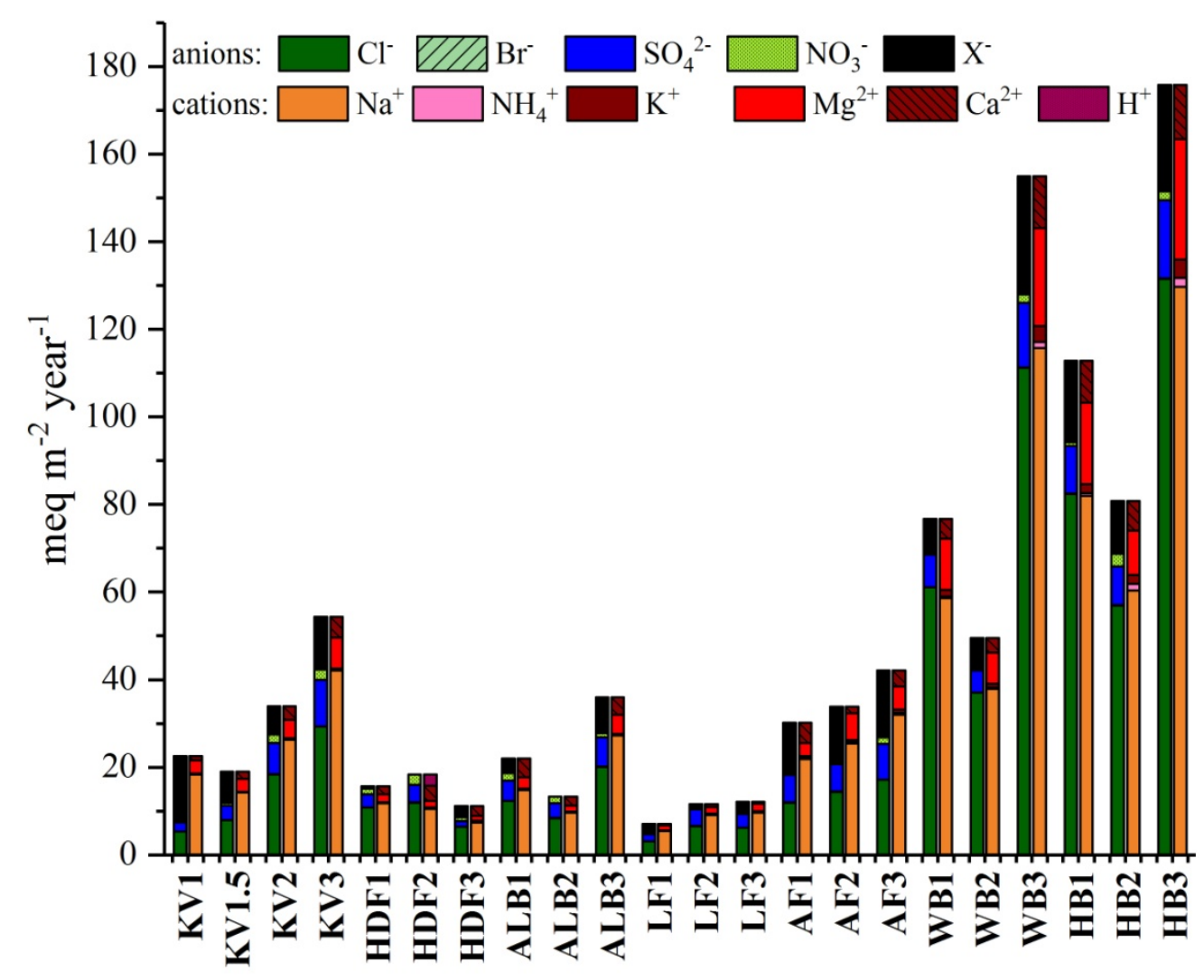


Figure S2. North Atlantic Chlorophyll-a concentration in April and May 2016. The data were obtained via an Aqua/MODIS NASA satellite continually orbiting the globe (https://neo.sci.gsfc.nasa.gov/view.php?datasetId=MY1DMM_CHLORA) with 1-month resolution and plots on the $\subset$ Google Earth platform. The data provides an estimate of the near-surface concentration of chlorophyll, calculated using an empirical relationship derived from in situ measurements of chlorophyll-a and remote sensing reflectance (Rrs) in the blue-to-green region of the visible spectrum.

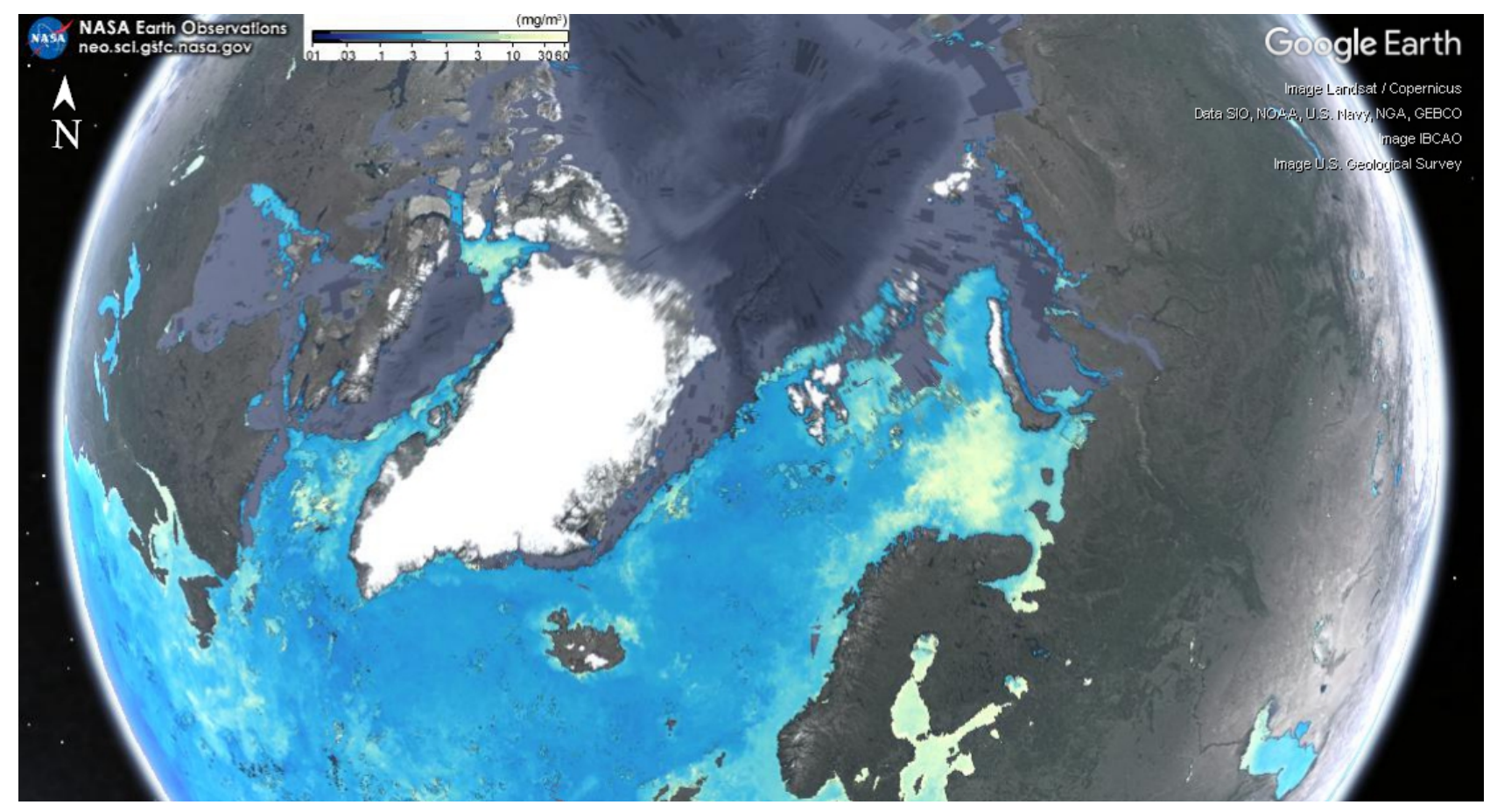


Figure S3. Bromide enrichment $\left(\mathrm{Br}_{\mathrm{enr}}\right)$, calculated for each glacier. The snow pits have been ordered from lower to higher $\mathrm{Br}_{\text {enr }}$ values (bottom panel; the dashed line indicates the referenced $\mathrm{Br} \backslash \mathrm{Na}$ sea-water ratio). The uppermost panel compares the $\mathrm{Br}_{\mathrm{enr}}$ and the altitude, the upper middle with longitude, and the lower middle with latitude.

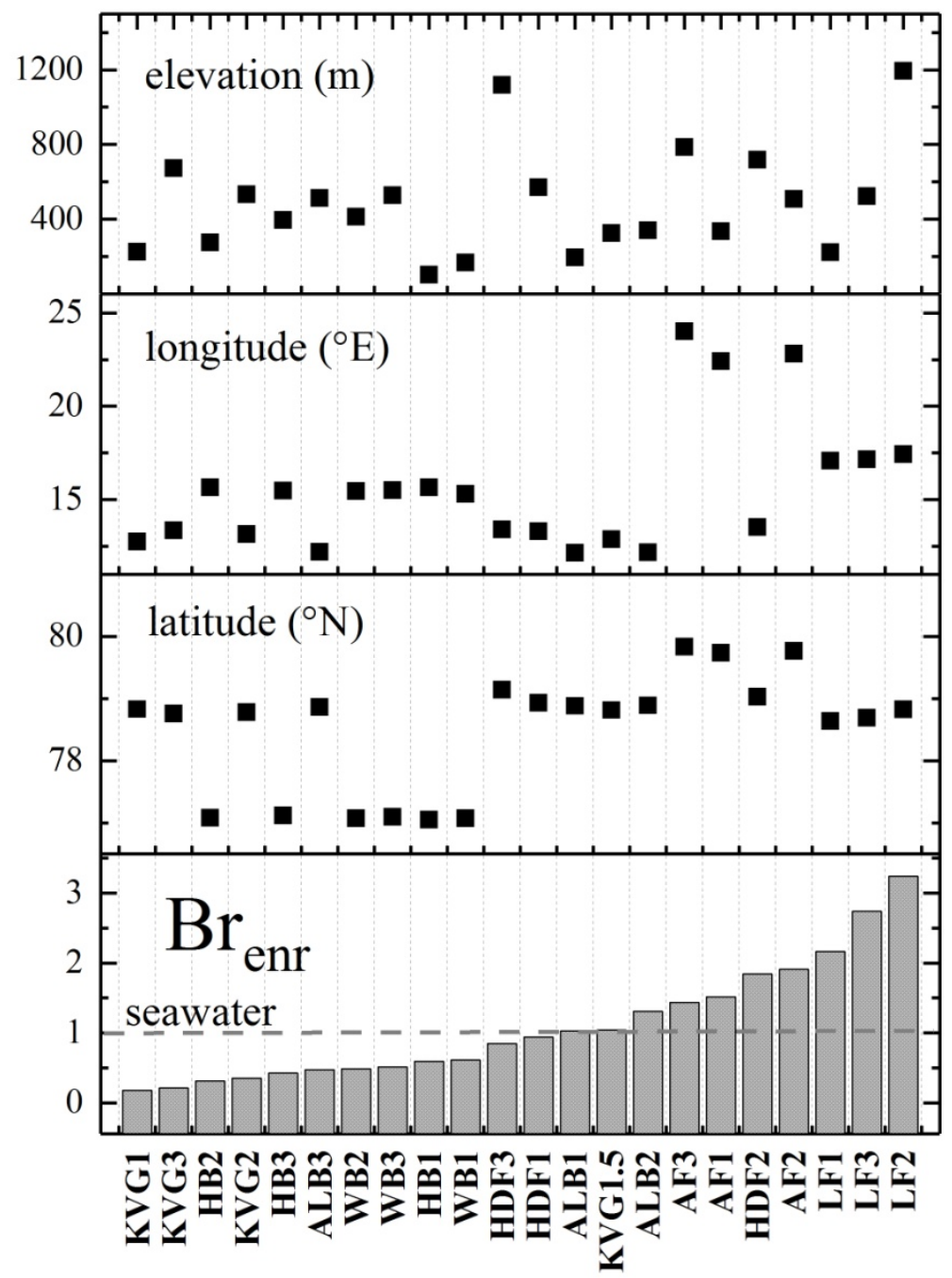


Figure S4. Vertical profiles of stratigraphy of snow pits collected on the top of each glacier.
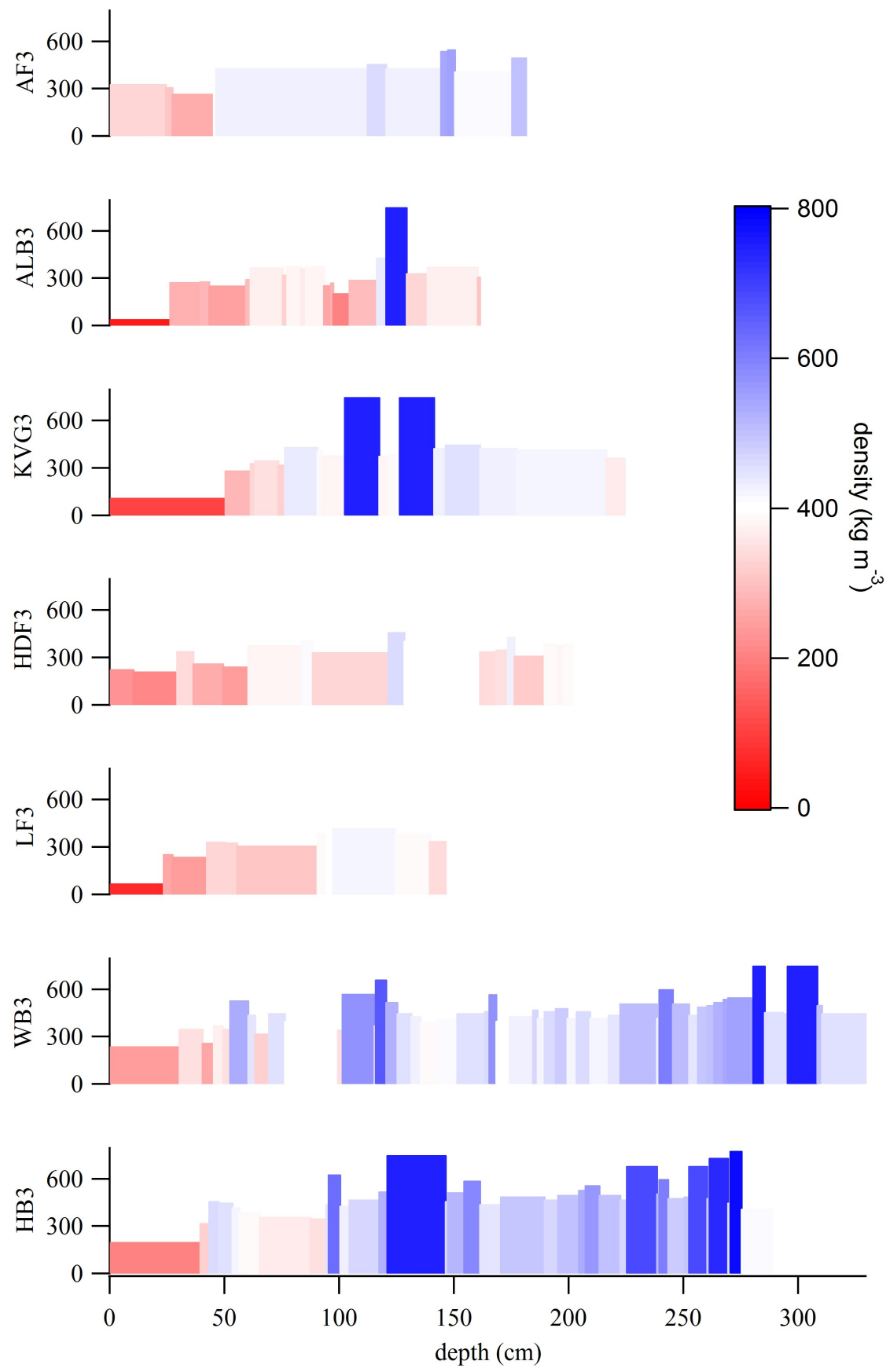